\title{
Social cognitive measures related to exercise behaviour: Validation in Indonesian middle-aged and older adults
}

\author{
Novita Intan Arovah ${ }^{\text {a, }}$, Kristiann C. Heesch ${ }^{\text {b }}$ \\ a Department of Sports Science, Sports Science Faculty, Yogyakarta State University, Yogyakarta, Indonesia \\ ${ }^{\mathrm{b}}$ School of Public Health and Social Work and Institute of Health and Biomedical Innovation, Queensland University of Technology, Brisbane, Australia
}

\section{A R T I C L E I N F O}

\section{Keywords:}

Correlates

Exercise

Physical activity

Psychometric testing

Social cognitive

Survey

\begin{abstract}
A B S T R A C T
Introduction: Evidence shows that exercise adoption and maintenance are influenced by social-cognitive processes. Instruments have been developed to measure these processes, but none have been validated for use in the Indonesian context. This study aimed to validate scales measuring social cognitive constructs related to exercise in Indonesian middle-aged and older population.

Methods: The Self-Efficacy for Exercise, the Exercise Self-Efficacy, the Multidimensional Outcome Expectations for Exercise, the Exercise Goal-Setting, the Exercise Planning and Scheduling, and the Social Support for Exercise Behavior scales underwent forward-backward translation, readability, and content validity assessments with middle-aged and older Indonesian adults $(n=126$; age $=61.2 \pm 8.2$ years, $72 \%$ female $)$. Psychometric testing included assessments of internal consistency and 1-week test-retest reliability, convergent validity, known-group validity with self-reported moderate to vigorous physical activity (MVPA), and construct validity using confirmatory factor analyses (CFA).

Results: The scales were found to be readable and content valid. Internal consistencies were acceptable to excellent (Cronbach's $\alpha=0.76-0.93$ ). Moderate to good repeatability estimates were demonstrated (ICC $=$ $0.72-0.88$ ). Convergent validity was supported by moderate correlations between scale scores and MVPA ( $\mathrm{r}=$ 0.42-0.72). Participants with sufficient MVPA levels consistently scored higher on scales than those with insufficient PA levels. The CFA showed a moderate fit for all scales except the Social Support for Exercise Behavior scale.

Conclusion: Although the factor structure of the Social Support scale warrants further investigation, the evidence supports the use of the six scales in Indonesian middle and older adults, including for evaluating the impact of theory-based physical activity interventions in this population.
\end{abstract}

\section{Introduction}

Physical inactivity is a leading cause of morbidity and premature mortality. ${ }^{1}$ Contributing 13.4 million DALYs (Disability-Adjusted Life Years) globally, it costs health care systems around the world $\$ 53.8$ billion. ${ }^{1}$ The economic burden due to high physical inactivity affects countries worldwide, including Indonesia. ${ }^{2}$ The global estimates of insufficient physical activity (PA) levels range from $15 \%$ in low-income countries to $29 \%$ in high-income countries. ${ }^{2}$ The latest Indonesian Basic Health Survey reveals that $22 \%$ of adults aged $45-49$ years are insufficiently active, and the prevalence of physical inactivity steadily increases as age increases, with $48 \%$ of adults aged $65+$ years being physically inactive. ${ }^{3}$ Thus, PA interventions in middle-aged and older adults are warranted for this population.

Promoting long-term PA behavior change is a challenging task. ${ }^{4}$ It requires behavior change strategies to influence social cognitive processes. According to Social Cognitive Theory, important constructs to influence PA behavior include self-efficacy, which is defined as confidence in being physically active even when faced with barriers ${ }^{5}$; outcome expectations, which are perceptions of the benefits of being physically active $^{6}$; self-regulation of PA behavior; and social support for PA from friends and family. ${ }^{7}$ These constructs have been shown to be the main predictors of exercise behavior. ${ }^{8}$

Scales that assess changes in these constructs pre- to post-

\footnotetext{
* Corresponding author. Department of Sports Science, Faculty of Sports Science, Yogyakarta State University, Colombo Street No 1, Karang Malang, Yogyakarta, 55281, Indonesia.

E-mail address: novita@uny.ac.id (N.I. Arovah).
} 
intervention have been developed in English or other Western languages. There are no scales that measure social cognitive constructs in the Indonesian language, and the validity and reliability of existing scales may not hold for the Indonesian population given social and ethnic differences. The development of new scales in the Indonesian language would require considerable time and resources; thus, adaptations of well-established scales are recommended. Moreover, the use of adapted scales allows for comparisons with studies from other settings.

Among the established scales for measuring social cognitive constructs are the Self-Efficacy for Exercise (SEE) ${ }^{5}$ and Exercise Self-Efficacy (EXSE) scales, ${ }^{9}$ the Multidimensional Outcome Expectations for Exercise (MOEE) scale, ${ }^{10}$ the Exercise Goal-Setting Scale (EGS), ${ }^{11}$ the Exercise Planning and Scheduling (EPS) scale, ${ }^{11}$ and the Social Support for Exercise Behaviours (SSEB) scale. ${ }^{12}$ This study aimed to cross-culturally adapt and then psychometrically test these scales in middle-aged and older Indonesian adults.

\section{Methods}

\subsection{Study design, participants and ethical clearance}

This study is a cross-sectional study conducted in April 2019. Participants were recruited from the membership of two community centres that offer health services to local middle-aged and older residents in Yogyakarta, Indonesia. Members were eligible to participate if they were literate in and able to comprehend the Indonesian language and aged $>45$ years. All participants provided written informed consent. The procedure was approved by the Human Ethics Committee of Gadjah Mada University (approval number: KE/0142/02/2019).

\subsection{Measures}

Social cognitive scales that exhibited excellent psychometric properties in previous studies, were well-used internationally, and were considered to be the most appropriate instruments for use in the target population were selected. These included two measures of self-efficacy, the $\mathrm{SEE}^{5}$ and $\mathrm{EXSE}^{9}$; one measure of outcome expectations, the MOEE, which has three subscales ${ }^{10}$; one measure of self-regulation, which has two subscales that are used separately, the EGS ${ }^{11}$ and EPS ${ }^{11}$; and one measure of social support, the SSEB, which combines three subscales. ${ }^{12}$
The scales' properties and their earlier psychometric testing results are shown in Table 1.

Other measures included demographic characteristics (age, sex, education level, marital status, employment status, and smoking status) and PA level, assessed with the validated interviewer-administered 7Day Recall. ${ }^{13}$

\subsection{Procedures}

This study followed a recommended protocol, which involved forward and backward translation of all five scales from the source language (English) to the target language (Indonesian/Bahasa), readability and content validity assessments, and psychometric testing. ${ }^{14}$ Fig. 1 illustrates the research procedures.

Forward and backward translations were conducted by six independent translators. The sample size for the readability study followed the recommendation of Sousa et al. ${ }^{14}$ for 10 to 40 participants. For this assessment, participants in one community center reviewed paper copies of the translated scales. They then responded to each item that they understood and indicated items for which the wording was unclear. Following standard practice, if all scale items were not understood by at least $80 \%$ of participants, the scale was to be revised by the translators until this criterion was met. ${ }^{14}$

Content validity assessment was conducted by a panel of five experts. Each panel member rated each item on (1) the relevance of the content to the local culture and (2) the clarity and equivalence of phrasing. The ratings were on a 4-point Likert scale from 1 (not relevant or equivalent) to 4 (very relevant or equivalent). The proportion of experts who gave each item a rating of 3 or 4 was calculated to determine the content equivalence (content-related validity) of each item of a scale. The proportion is called the item content validity index, and a value of 0.78 or more indicates an acceptable content-related validity of an item. ${ }^{14}$ Items with values below this level were revised by the experts and re-evaluated for readability and content validity.

To assess convergent and construct validity, paper copies of the translated scales were administered in-person to participants at the second community center for self-completion. The sample size needed for testing validity was based on the ratio of the number of cases to the number of parameters that require statistical estimates of $5: 1$ for confirmatory factor analysis. ${ }^{15,16}$ The highest number of items in the

Table 1

Summary of the social cognitive scales.

\begin{tabular}{|c|c|c|c|c|}
\hline Constructs & Scales & Items & Response option & $\begin{array}{l}\text { Psychometric properties from } \\
\text { previous studies }\end{array}$ \\
\hline \multirow[t]{2}{*}{ Self-efficacy } & $\mathrm{SEE}^{5}$ & $\begin{array}{l}9 \text { items measuring confidence in exercising at least } 3 \text { times } \\
\text { per week for } 20 \text { min during adverse conditions }\end{array}$ & $\begin{array}{l}10 \text {-Likert scale from } 1 \text { (not confident) to } \\
10 \text { (very confident). }\end{array}$ & Cronbach's $\alpha=0.92$ \\
\hline & EXSE $^{9}$ & $\begin{array}{l}8 \text { items measuring ability to exercise at moderate intensity at } \\
\text { least } 3 \text { times per week, with }\end{array}$ & & Cronbach's $\alpha=0.88$ \\
\hline $\begin{array}{l}\text { Outcome } \\
\text { expectation }\end{array}$ & $\begin{array}{l}\text { MOEE }^{10} \text { with } 3 \\
\text { subscales }\end{array}$ & $\begin{array}{l}6 \text { physical outcome expectation items } \\
4 \text { social outcome expectation items } \\
5 \text { self-evaluative outcome expectation items }\end{array}$ & $\begin{array}{l}5 \text { Likert scale from } 1 \text { (strongly disagree) } \\
\text { to } 5 \text { (strongly agree) }\end{array}$ & $\begin{array}{l}\text { Cronbach's } \alpha=0.82 \\
\text { Cronbach's } \alpha=0.81 \\
\text { Cronbach's } \alpha=0.84\end{array}$ \\
\hline \multirow[t]{2}{*}{ Self-Regulation } & $\mathrm{EGS}^{11}$ & 10 items in goal setting & $\begin{array}{l}5 \text { Likert scale from } 1 \text { (does not describe) } \\
\text { to } 5 \text { (describes completely) }\end{array}$ & $\begin{array}{l}\text { Cronbach's } \alpha=0.89 \\
\text { 1-week repeatability: ICC }= \\
0.87\end{array}$ \\
\hline & EPS $^{11}$ & 10 items in planning and schedule & & $\begin{array}{l}\text { Cronbach's } \alpha=0.89 \\
\text { 1-week repeatability: ICC }= \\
0.87\end{array}$ \\
\hline \multirow[t]{3}{*}{ Social Support } & $\begin{array}{l}\text { SSEB }^{12} \text { with } 3 \\
\text { subscales }\end{array}$ & 10 friends' support items & $\begin{array}{l}5 \text { Likert scale from } 1 \text { (none) to } 5 \text { (very } \\
\text { often). }\end{array}$ & $\begin{array}{l}\text { Cronbach's } \alpha=0.84 \\
\text { 1-week repeatability: ICC }= \\
0.79\end{array}$ \\
\hline & & 10 family participation and encouragement items & & $\begin{array}{l}\text { Cronbach's } \alpha=0.91 \\
\text { 1-week repeatability: ICC }= \\
0.77\end{array}$ \\
\hline & & 3 family reward and punishment items & & $\begin{array}{l}\text { Cronbach's } \alpha=0.61 \\
\text { 1-week repeatability: ICC }= \\
0.55\end{array}$ \\
\hline
\end{tabular}

Note. EGS = Exercise Goal-Setting Scale. EPS = Exercise Planning and Scheduling. EXSE $=$ Exercise Self-Efficacy. ICC=Intraclass correlation. MOEE $=$ Multidimensional Outcome Expectations for Exercise. SEE=Self-Efficacy for Exercise. SSEB=Social Support for Exercise Behaviours. 


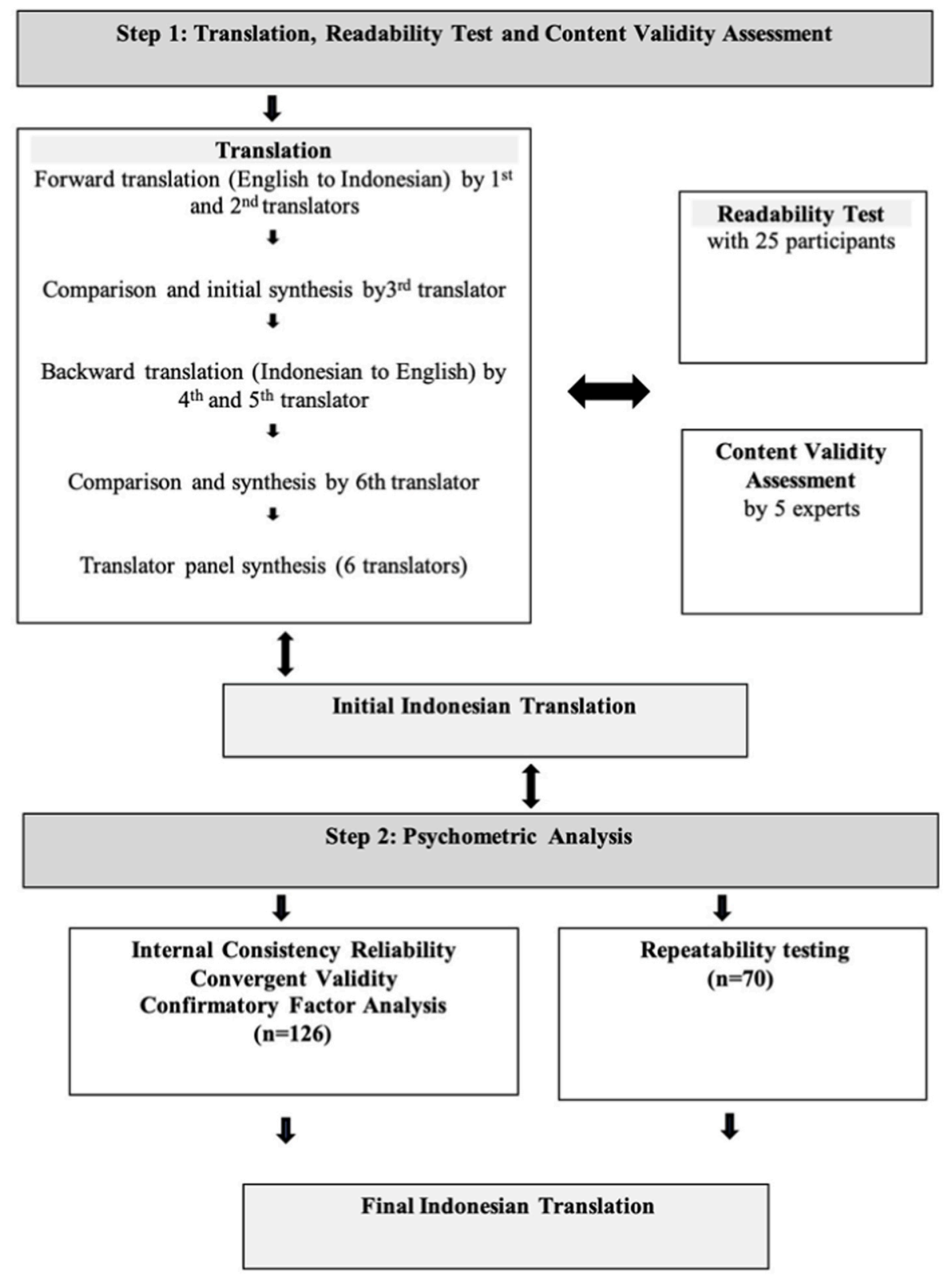

Fig. 1. Legends: The instrument cross-cultural adaptation process.

scales adapted in this study was the SSEB, which consisted of 23 items. Thus, the minimum sample required for the analysis was 115 participants. The number of participants recruited exceeded this number. ${ }^{14} \mathrm{~A}$ subsample of participants who completed the initial assessment returned for a second assessment one week later to complete the scales again for a 1-week test and retest reliability assessment.

\subsection{Statistical analysis for psychometric testing}

Pearson's chi-square test was used to compare the characteristics of participants who completed the readability assessment to those of participants who completed the psychometric testing. For the psychometric testing, first, reverse coding of inversely-worded items was conducted. Next, Cronbach's $\alpha$ was computed to assess internal consistency reliability of the scales. The commonly-used threshold of alpha $\geq 0.70$ was selected to indicate acceptable reliability while a corrected item-total correlation above 0.40 indicated good discrimination of an item. ${ }^{17}$ To measure 1-week test-retest reliability, intraclass correlation coefficients
(ICCs) were calculated for each score using the one-way random average ICC model. ICC values $<0.50$ were considered poor; $0.50-0.75$ moderate; $0.75-0.90$ good; and $>0.90$ excellent. $^{18}$

For convergent validity assessment, we computed Pearson's Product correlations between each scale score and time spent in engaging in moderate and vigorous PA in the previous week. For the known-group validity testing, participants were classified as meeting PA recommendations if they had engaged in at least 150 min of moderate PA or 75 min of vigorous PA, ${ }^{19}$ and independent sample t-tests were computed to compare scale scores between these groups.

Last, we conducted confirmatory factor analysis (CFA), to assess the construct validity of each scale. We evaluated the model fit of the data according to the hypothetic structure informed by the initial developers of each scale based on the maximum likelihood. An acceptable model fit was indicated by several goodness of fit indices. First was the $\chi^{2} /$ degree of freedom (df) ratio for which a value $<3$ indicated good fit. Second was the root mean square error of approximation (RMSEA). A value $<$ 0.08 indicated good fit; a value between 0.08 and 0.10 indicated 
mediocre fit; and a value $>0.10$ indicated poor fit. ${ }^{20}$ Also calculated were the comparative fit index (CFI), Tucker-Lewis index (TLI), and the standardized root mean square residual (SRMR) ${ }^{20}$ Values greater $>0.90$ on the CFI and TLI and values $<0.08$ on the SRMR indicated an adequate fit between the hypothesized model and the observed data. ${ }^{20}$

Data were analyzed using SPSS ${ }^{\circledR}$ v21.0 (IBM, Chicago, IL, US), except for the CFA analyses, for which STATA v15 (College Station, TX, US) was used. A p-value $<0.05$ represented statistical significance.

\section{Results}

\subsection{Participant characteristics}

Twenty-five members of one community center (mean age: $59.3 \pm$ 7.5 years) completed the readability assessment. Another 126 members of the second community center (mean age: $61.6 \pm 8.3$ years) completed the psychometric testing, and of these, 70 (mean age: $62.9 \pm 7.6$ years) also completed the test re-test reliability assessment. Table 2 shows that the characteristics of participants were similar across steps of the protocol. In brief, most participants were women, married, educated at a secondary level, non-smokers, and unemployed or retired. Most participants in the psychometric testing met recommended PA levels. PA level was not measured among participants in the readability assessment.

\subsection{Translation, readability, and content validity assessments}

A minor modification was made during the translation process to the response options of the EGS and EPS. The scales' original response options, which ranged from 'does not describe completely' to 'describe completely', were modified to 'never', 'rarely', 'a few times', 'often' or 'very often' a participant did the activity described in the item statement. It was expected that these options would be easier for participants to answer because they are more commonly used in the Indonesian language. After this change, all translated scales met the requirement outlined by Sousa et al. ${ }^{14}$ that all items of a scale be understood by at least $80 \%$ of participants. Experts consistently gave positive feedback by

Table 2

Participants' sociodemographic characteristics and physical activity status.

\begin{tabular}{|c|c|c|c|}
\hline \multirow[t]{2}{*}{ Variables } & \multirow{2}{*}{$\begin{array}{l}\text { Readability } \\
\text { assessment }(\mathrm{n}=25) \\
\mathrm{n}(\%)\end{array}$} & \multirow{2}{*}{$\begin{array}{l}\text { Internal consistency } \\
\text { study }(\mathrm{n}=126) \\
\mathrm{n}(\%)\end{array}$} & \multirow{2}{*}{$\begin{array}{l}\text { Test-retest } \\
\text { study (n= } \\
70) \\
\mathrm{n}(\%)\end{array}$} \\
\hline & & & \\
\hline \multicolumn{4}{|l|}{ Sex } \\
\hline Female & $16(64)$ & $93(74)$ & $59(84)$ \\
\hline Male & $9(36)$ & $33(26)$ & $11(16)$ \\
\hline \multicolumn{4}{|l|}{ Age (years) } \\
\hline $40-50$ & $2(8)$ & $16(13)$ & $5(7)$ \\
\hline $51-60$ & $4(16)$ & $35(28)$ & $17(24)$ \\
\hline $61-70$ & $12(48)$ & $58(46)$ & $38(54)$ \\
\hline $71-80$ & $2(8)$ & 17 (14) & $10(15)$ \\
\hline \multicolumn{4}{|l|}{ Marital status } \\
\hline Married & $21(84)$ & $91(72)$ & $49(70)$ \\
\hline $\begin{array}{c}\text { Not married/ } \\
\text { widowed }\end{array}$ & $4(16)$ & $33(28)$ & $21(30)$ \\
\hline \multicolumn{4}{|c|}{ Highest education level } \\
\hline Primary & $2(8)$ & $18(14)$ & $11(16)$ \\
\hline Secondary & $12(48)$ & $58(45)$ & $34(49)$ \\
\hline Tertiary & $11(44)$ & $52(41)$ & $25(36)$ \\
\hline \multicolumn{4}{|c|}{ Employment status } \\
\hline Employed & $6(24)$ & $14(11)$ & $6(9)$ \\
\hline $\begin{array}{l}\text { Unemployed/ } \\
\text { retired }\end{array}$ & $19(76)$ & $112(89)$ & $64(91)$ \\
\hline \multicolumn{4}{|c|}{ Physical activity $^{\mathrm{a}}$} \\
\hline Sufficient & - & 74 (59) & $42(60)$ \\
\hline Insufficient & - & $52(41)$ & $28(40)$ \\
\hline
\end{tabular}

a Participants were classified as sufficiently active if they engaged in at least 150 min of moderate physical activity or 75 min of vigorous physical activity in the previous week. rating all items as either 3 or 4 for equivalency and relevance, indicating that all items had acceptable content validity. Therefore, no further adjustments were made.

\subsection{Psychometric testing}

As shown in Table 3, internal consistency of all scales ranged from acceptable to excellent (Cronbach $\alpha=0.76-0.94$ ). No corrected itemtotal correlation was $<0.40$; thus, all items were retained. The repeatability coefficients were moderate to good (ICCs $=0.72-0.85$ ). Positive, moderate correlations between each score and PA were found $(\mathrm{r}=$ 0.42-0.72). Participants who met PA recommendations scored higher than those who did not on all social cognitive measures $(\mathrm{p}<0.01)$.

Table 4 shows the model fit parameters for each scale. All $\chi / \mathrm{df}$ ratios were $<3.0$, and RMSEAs were between 0.09 and 0.10, except for the $\operatorname{SSEB}(\chi / \mathrm{df}$ ratio $=3.78$; RMSEA $=0.14)$. Thus, there was a moderate fit for all scales except the SSEB, for which there was a poor fit.

\section{Discussion}

Valid and reliable social cognitive scales are needed in Indonesia for monitoring, evaluating, and intervening to change exercise behaviour. This study was the first to cross-culturally adapt selected social cognitive scales for use in the Indonesian population. The study resulted in the Indonesian and English language versions of the scales being semantically similar. The translated version resulted in excellent readability and content validity among middle-aged and older adults. These findings indicate that the constructs measured in the selected scales are transferable to the Indonesian context. This study also showed that the Indonesian translated versions of the scales have satisfactory psychometric properties.

The internal consistency of the Indonesian version of the SEE scale was good ( $\alpha=0.88$ ). It was higher than the estimate reported for a study in Taiwan $(\alpha=0.72)$ in predominantly male participants, aged $60-91$ years, who were mostly physically active and city dwellers, ${ }^{21}$ but lower than the estimate reported in a study in China $(\alpha=0.95)$, which was conducted in a younger population with cardiovascular disease. ${ }^{22}$ Our estimate was comparable to the one reported for the initial study that tested the psychometric properties of the scale in the US $(\alpha=0.92)$. That study recruited elderly living in a continuing care retirement community and was interviewer-administered, ${ }^{5}$ whereas we recruited community-dwelling middle-aged to older adults who tended to be more physically active. The differences in the study participants' characteristics among those studies may contribute to the variety of findings. Nonetheless, all resulted in acceptable estimates of internal consistency. Our study also resulted in a good 1-week test and retest reliability, which supports the finding from a study in an older population in Sweden. ${ }^{23}$ In addition, a moderate fit of our data using the original one-factor structure was found, thus supporting findings from studies in China ${ }^{21}$ and in African American and Latino older adults in the US. ${ }^{24}$

Self-efficacy was also measured with the EXSE scale. Our internal reliability estimates were comparable to those initially reported. ${ }^{9}$ High internal consistency $(\alpha=0.92)$ of the scale was also reported in a population with multiple sclerosis in the US. ${ }^{25}$ We also found good 1-week test and retest reliability and a fair fit of the data using the original one-factor structure. The scale has been widely used in the US ${ }^{26}$ and Europe, ${ }^{27}$ but to our knowledge, no other validation study has been conducted for this scale. Our study, thus, extends the evidence in the literature to support the use of this scale in an Asian population, namely Indonesian middle-aged and older adults.

Outcome expectations were measured with the MOEE scale. ${ }^{10}$ Our study showed that the physical and social subscales have acceptable internal consistency reliability and the self-evaluative subscale has good internal consistency reliability; these findings corroborate findings from studies conducted in the US in continuing-care retirement communities ${ }^{28}$ and in community-dwelling adults with multiple sclerosis. ${ }^{25}$ Our 
Table 3

Estimates of reliability, convergent validity of social cognitive scale scores.

\begin{tabular}{|c|c|c|c|c|c|c|c|}
\hline \multirow{2}{*}{$\begin{array}{l}\text { Constructs, scales and subscales } \\
\text { Scales }\end{array}$} & \multicolumn{2}{|l|}{ Reliability } & \multicolumn{2}{|c|}{ Convergent validity } & \multicolumn{3}{|c|}{ Known group validity } \\
\hline & Cronbach's $\alpha$ & ICC (95\%CI) & Correlation $^{\mathrm{a}}$ & p-value & $\begin{array}{l}\text { Sufficient PA } \\
\text { Mean } \pm \text { SE }\end{array}$ & $\begin{array}{l}\text { Insufficient PA } \\
\text { Mean } \pm \text { SE }\end{array}$ & p-value \\
\hline \multicolumn{8}{|l|}{ Self-efficacy } \\
\hline In overcoming PA barriers (SEE) & 0.88 & $0.75(0.65-0.83)$ & 0.72 & $<0.001$ & $6.35 \pm 0.14$ & $4.15 \pm 0.21$ & $<0.001$ \\
\hline In PA engagement (EXSE) & 0.87 & $0.88(0.81-0.93)$ & 0.60 & $<0.001$ & $5.47 \pm 0.17$ & $3.67 \pm 0.20$ & $<0.001$ \\
\hline \multicolumn{8}{|l|}{ Outcome expectations (MOEE) } \\
\hline Physical subscale & 0.76 & $0.83(0.73-0.89)$ & 0.50 & $<0.001$ & $3.82 \pm 0.08$ & $3.48 \pm 0.10$ & 0.005 \\
\hline Social subscale & 0.76 & $0.84(0.75-0.92)$ & 0.47 & $<0.001$ & $3.99 \pm 0.07$ & $3.31 \pm 0.10$ & $<0.001$ \\
\hline Self-evaluative subscale & 0.83 & $0.72(0.59-0.82)$ & 0.42 & $<0.001$ & $3.93 \pm 0.08$ & $3.36 \pm 0.11$ & $<0.001$ \\
\hline \multicolumn{8}{|l|}{ Self-regulation } \\
\hline Goal setting (EGS) & 0.94 & $0.85(0.75-0.90)$ & 0.64 & $<0.001$ & $2.95 \pm 0.11$ & $1.81 \pm 0.90$ & $<0.001$ \\
\hline Planning and scheduling (EPS) & 0.83 & $0.77(0.63-0.86)$ & 0.65 & $<0.001$ & $2.87 \pm 0.07$ & $1.92 \pm 0.09$ & $<0.001$ \\
\hline \multicolumn{8}{|l|}{ Social support (SSEB) } \\
\hline Family participation and involvement subscale & 0.90 & $0.79(0.67-0.87)$ & 0.49 & $<0.001$ & $2.78 \pm 0.10$ & $2.00 \pm 0.10$ & $<0.001$ \\
\hline Family reward and punishment subscale & 0.80 & $0.76(0.61-0,85)$ & 0.51 & $<0.001$ & $2.06 \pm 0.12$ & $1.59 \pm 0.09$ & 0.002 \\
\hline Friends' participation and punishment subscale & 0.93 & $0.73(0.57-0.83)$ & 0.64 & $<0.001$ & $2.90 \pm 0.09$ & $2.01 \pm 0.10$ & $<0.001$ \\
\hline
\end{tabular}

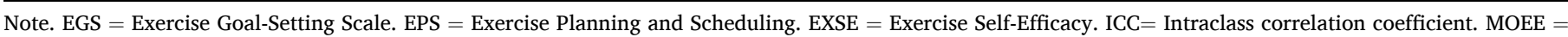

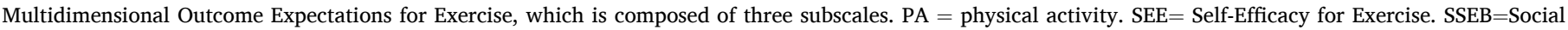
Support for Exercise Behaviours, which is composed of three subscales.

a Correlation with moderate- and vigorous-intensity physical activity.

b Engaged in at least 150 min of moderate-intensity physical activity or 75 min of vigorous-intensity physical activity in the previous week.

Table 4

Results of confirmatory factor analysis: Model-fit parameters of social cognitive scales $(\mathrm{n}=126)$.

\begin{tabular}{llllll}
\hline Scales & $\begin{array}{l}\chi / \mathrm{df} \\
\text { ratio }\end{array}$ & RMSEA & CFI & TLI & SRMR \\
\hline $\begin{array}{l}\text { Self-efficacy in overcoming PA } \\
\text { barriers (SEE) }\end{array}$ & 2.02 & 0.09 & 0.94 & 0.94 & 0.06 \\
$\begin{array}{l}\text { Self-efficacy in PA engagement } \\
\quad \text { EXSE) }\end{array}$ & 2.02 & 0.09 & 0.93 & 0.90 & 0.06 \\
$\begin{array}{l}\text { Outcome expectations (MOEE) } \\
\text { Self-regulation (EPS and EGS) }\end{array}$ & 2.35 & 0.10 & 0.85 & 0.83 & 0.07 \\
Social support (SSEB) & 2.39 & 0.10 & 0.90 & 0.85 & 0.07 \\
\hline
\end{tabular}

Note: EXSE = Exercise Self-Efficacy. EGS = Exercise Goal-Setting Scale. EPS = Exercise Planning and Scheduling. MOEE = Multidimensional Outcome Expectations for Exercise. PA = physical activity. SEE=Self-Efficacy for Exercise. $\mathrm{SSEB}=$ Social Support for Exercise Behaviours, $\chi / \mathrm{df}$ ratio $=$ Chi-square divided by degree of freedom. RMSEA = Root mean squared error of approximation. $\mathrm{CFI}=$ Comparative fit index. TLI $=$ Tucker-Lewis index. SRMR $=$ Standardized root mean square residual.

reliability estimates are also comparable to the estimates reported for the initial development of the English version of the scale. ${ }^{10}$ Our study also showed that each subscale has good test-retest reliability. The original three-factor structure, however, only moderately fit the data, with a RMSEA of 0.10 . Similarly, a mediocre fit of the original structure was reported by Hall et al. ${ }^{28}$ who preceded with the deletion of items with low factor loadings and conducted a subsequent CFA on the remaining items. The result was a better fit of the data. However, these researchers recommended that these items be retained pending additional validity and factorial invariance testing in other samples and over time. We support the retention of all items to allow direct comparison to be made across studies. Moreover, McAuley et al. ${ }^{25}$ reported a reasonable fit for the original 3-factor solution among multi-sclerosis patients after rerunning the model with a correlation between the residuals of two social outcome expectations items that appeared to overlap. Exploration of modification indices to obtain a suitable algorithm for interpreting the scales for specific populations; thus, the MOEE is recommended including in Indonesian middle-aged and older populations.

Minor modifications to the response options that were made to the self-regulation subscales, the EGS and the EPS, resulted in acceptable to good internal consistency reliability and test-retest reliability. These findings support those reported for the initial study. ${ }^{11}$ Two studies conducted among undergraduate students in the $\mathrm{US}^{29}$ and Thailand, ${ }^{30}$ however, suggested that EPS contains two subscales. Elavsky et al. ${ }^{29}$ labelled the subscales 'deprioritizing' and 'planning-schedule' following modification indices from CFA, whereas Sriramatr et al. ${ }^{30}$ introduced the idea that the two subscales represent positive and negative EPS, after extracting factors in a principal component analysis. Their approaches appeared to be justified as following this proposed structure, they reported acceptable reliability for their three subscales, and the 3-factor structure resulted in a good fit of the data, in contrast with our findings of a moderate fit for the original 2-factor structure. These findings suggest that further exploration of the scale's factor structure may improve the fit of the data in Indonesian populations.

The SSEB subscales were also shown to have acceptable internal consistency reliability. Our reliability estimates were comparable to those found for a US study, ${ }^{31}$ but our estimate for the family reward and punishment subscale ( $\alpha=0.80$ ) was much higher than the estimate reported by the US scale developer $(\alpha=0.61) .{ }^{12}$ Differences in estimates may reflect stronger roles for Indonesian families in providing rewards and punishments for modifying individual behavior like physical activity than seen in Western cultures. ${ }^{12}$ However, the US researchers reported a better fit of the data than we found using the same approach. That approach was to allow correlation among factors but with the omission of two items with low factor loadings. Model modification for this scale could improve the fit of the data in Indonesian populations.

We found moderate to high correlations between scale scores and PA, thus supporting the convergent validity of the scales. Likewise, known-group validity was supported as the participants who met the PA recommendation scored consistently higher on all social cognitive scales than participants who did not meet this recommendation. This finding supports those of other studies that have posited the importance of the relationship of social cognitive processes to PA behaviors. ${ }^{6}$

The main strength of this study was the use of a comprehensive process of cross-cultural adaptation of measures for adopting well-used scales into a new context. However, there are notable limitations. First, due to time and resource limitations, the sample size for the CFA was based on five participants per number of items/parameters, which is a minimal sample size requirement for CFA analysis. ${ }^{15}$ The recommended minimum sample size for CFA is 200 participants, or at least 10 participants per parameter. ${ }^{32}$ We did not examine the modification indices in the CFA as we recognized that attempts to modify the factor structure were limited by our modest sample size. Second, the study was conducted in a community-dwelling setting, thereby limiting the generalization to other populations including adults in residential care and 
younger adults. This study was also likely to attract participants who had an interest in PA, which would also limit the study's generalizability, although participants were sufficiently heterogeneous in their level of PA to produce acceptable reliability estimates. Third, our study was limited by the cross-sectional nature of the data; further validation studies that employ longitudinal designs for assessing the predictive validity and responsiveness to change are recommended.

\section{Conclusion}

The overall findings provide evidence of readability, reliability, content validity, convergent, and construct validity of the measures. The findings substantiate the applicability of the Indonesian versions of social cognitive scales related to exercise behavior in Indonesian middleaged and older adults. It is expected that the adapted scales will be useful for evaluating the impact of theory-based exercise interventions, as well as for identifying and developing evidence-based recommendations for promoting exercise to improve health and well-being, based on social cognitive processes associated with exercise adoption and maintenance in this population.

\section{Funding}

This study was funded by a Post-Doctoral Research Grant 2020 from Yogyakarta State University Indonesia No 10/Penelitian/Pasca Doktor/ UN34.21/2019.

\section{Declaration of competing interest}

The authors declare that they have no competing interests.

\section{References}

1 Lee I-M, Shiroma EJ, Lobelo F, Puska P, Blair SN, Katzmarzyk PT. Effect of physical inactivity on major non-communicable diseases worldwide: an analysis of burden of disease and life expectancy. Lancet. 2012;380(9838):219-229. https://doi.org/ 10.1016/S0140-6736(12)61031-9.

2 Sallis JF, Bull F, Guthold R, et al. Progress in physical activity over the Olympic quadrennium. Lancet. 2016;388(10051):1325-1336. https://doi.org/10.1016/ S0140-6736(16)30581-5.

3 Indonesia Ministry of Health. Basic Health Survey - 2018. Jakarta: Kementrian Kesehatan Republik Indonesia; 2018.

4 O'Brien N, McDonald S, Araújo-Soares V, et al. The features of interventions associated with long-term effectiveness of physical activity interventions in adults aged 55-70 years: a systematic review and meta-analysis. Health Psychol Rev. 2015;9 (4):417-433.

5 Resnick B, Jenkins LS. Testing the reliability and validity of the self-efficacy for exercise scale. Nurs Res. 2000;49(3):154-159.

6 Joseph R, Ainsworth B, Mathis L, Hooker S, Keller C. Utility of social cognitive theory in intervention design for promoting physical activity among African-American women: a qualitative study. Am J Health Behav. 2017;41(5):518. https://doi.org/ 10.5993/A.JHB.41.5.1.

7 Samdal GB, Eide GE, Barth T, Williams G, Meland E. Effective behaviour change techniques for physical activity and healthy eating in overweight and obese adults: systematic review and meta-regression analyses. Int J Behav Nutr Phys Activ. 2017;14 (1):42.

8 Tudor-Locke, Bell R, Myers A, et al. Controlled outcome evaluation of the First Step Program: a daily physical activity intervention for individuals with type II diabetes. Int J Obes. 2004;28(1):113-119. https://doi.org/10.1038/sj.ijo.0802485.
9 McAuley E. Self-efficacy and the maintenance of exercise participation in older adults. J Behav Med. 1993;16(1):103-113.

10 Wójcicki TR, White SM, McAuley E. Assessing outcome expectations in older adults: the multidimensional outcome expectations for exercise scale. J Gerontol B Psychol Sci Soc Sci. 2009;64(1):33-40.

11 Rovniak LS, Anderson ES, Winett RA, Stephens RS. Social cognitive determinants of physical activity in young adults: a prospective structural equation analysis. Ann Behav Med. 2002;24(2):149-156. https://doi.org/10.1207/S15324796ABM2402_12.

12 Sallis JF, Grossman RM, Pinski RB, Patterson TL, Nader PR. The development of scales to measure social support for diet and exercise behaviors. Prev Med. 1987;16 (6):825-836.

13 Sallis JF, Haskell WL, Wood PD, et al. Physical activity assessment methodology in the Five-City Project. Am J Epidemiol. 1985;121(1):91-106.

14 Sousa VD, Rojjanasrirat W. Translation, adaptation and validation of instruments or scales for use in cross-cultural health care research: a clear and user-friendly guideline. J Eval Clin Pract. 2011;17(2):268-274. https://doi.org/10.1111/j.13652753.2010.01434.x.

15 Bentler PM, Chou C-P. Practical issues in structural modeling. Socio Methods Res. 1987;16(1):78-117.

16 Bentler PM, Yuan K-H. Structural equation modeling with small samples: test statistics. Multivariate Behav Res. 1999;34(2):181-197.

17 Gliem RR, Gliem JA. Calculating, Interpreting, and Reporting Cronbach's Alpha Reliability Coefficient for Likert-type Scales: Midwest Research-To-Practice Conference in Adult. Continuing, and Community Education; 2003.

18 Koo TK, Li MY. A guideline of selecting and reporting intraclass correlation coefficients for reliability research. J Chiropr Med. 2016;15(2):155-163.

19 World Health Organization. Global Recommendations on Physical Activity for Health. World Health Organization; 2010.

$20 \mathrm{Hu}$ Lt, Bentler PM. Cutoff criteria for fit indexes in covariance structure analysis: conventional criteria versus new alternatives. Struct Equ Model: A Multidiscip J. 1999; 6(1):1-55.

21 Lee L-L, Perng S-J, Ho C-C, Hsu H-M, Lau S-C, Arthur A. A preliminary reliability and validity study of the Chinese version of the self-efficacy for exercise scale for older adults. Int J Nurs Stud. 2009;46(2):230-238.

22 Taylor-Piliae RE, Froelicher ES. Measurement properties of Tai Chi exercise selfefficacy among ethnic Chinese with coronary heart disease risk factors: a pilot study. Eur J Cardiovasc Nurs. 2004;3(4):287-294.

23 Rydwik E, Hovmöller F, Boström C. Aspects of reliability and validity of the Swedish version of the Self-Efficacy for Exercise Scale for older people. Physiother Theory Pract. 2014:30(2):131-137.

24 Resnick B, Luisi D, Vogel A, Junaleepa P. Reliability and validity of the self-efficacy for exercise and outcome expectations for exercise scales with minority older adults. J Nurs Meas. 2004;12(3):235-248.

25 McAuley E, Motl RW, White SM, Wójcicki TR. Validation of the multidimensional outcome expectations for exercise scale in ambulatory, symptom-free persons with multiple sclerosis. Arch Phys Med Rehabil. 2010;91(1):100-105.

26 Elavsky S, McAuley E, Motl RW, et al. Physical activity enhances long-term quality of life in older adults: efficacy, esteem, and affective influences. Ann Behav Med. 2005; 30(2):138-145.

27 Mudrak J, Stochl J, Slepicka P, Elavsky S. Physical activity, self-efficacy, and quality of life in older Czech adults. Eur J Ageing. 2016;13(1):5-14.

28 Hall KS, Wójcicki TR, Phillips SM, McAuley E. Validity of the multidimensional outcome expectations for exercise scale in continuing-care retirement communities. J Aging Phys Activ. 2012;20(4):456-468.

29 Elavsky S, Doerksen SE, Conroy DE. Identifying priorities among goals and plans: a critical psychometric reexamination of the exercise goal-setting and planning/ scheduling scales. Sport Exerc.Perform. Psychol. 2012;1(3):158.

30 Sriramatr S, Berry TR, Rodgers WM. Validity and reliability of Thai versions of questionnaires measuring leisure-time physical activity, exercise-related selfefficacy, outcome expectations and self-regulation. Pacific Rim Int J Nurs Res. 2013; 17(3):203-216.

31 Treiber FA, Baranowski T, Braden DS, Strong WB, Levy M, Knox W. Social support for exercise: relationship to physical activity in young adults. Prev Med. 1991;20(6): 737-750.

32 Kline RB. Principles and Practice of Structural Equation Modeling. Guilford Publications; 2011. 